\title{
Insulation Properties of PMMA:TiO2 Nanodielectric Film for High Voltage Applications
}

\author{
Melvin Welan Mathew ${ }^{1}$, Lyly Nyl Ismail ${ }^{2}$, Norsabrina Sihab ${ }^{3}$, Ahmad Asri Abd Samad ${ }^{4}$, \\ Nur Ashida Salim ${ }^{5}$ \\ 1,2,3,4 Faculty of Electrical Engineering, UiTM Cawangan Pulau Pinang, Jalan Permatang Pauh, 13500 Seberang Perai, \\ Pulau Pinang \\ ${ }^{5}$ Faculty of Electrical Engineering, Universiti Teknologi MARA (UiTM), Malaysia
}

\begin{abstract}
Article Info
Article history:

Received Jun 4, 2018

Revised Aug 2, 2018

Accepted Aug 10, 2018

\section{Keywords:}

PMMA:TiO2 nanocomposite

film

HV

AC Bbreakdown

DC breakdown

partial discharge

ABSTRACT

This research investigates the insulation properties of poly methyl methacrylate with titanium dioxide (PMMA:TiO2) nanodielectric film to be used as insulation layer in high voltage (HV) applications. AC and DC breakdown test has been conducted to investigate the insulation properties of PMMA:TiO2 nanodielectric to be used as solid insulation in HV. In this research, the PMMA:TiO2 nanodielectric film were prepared by varying the annealing temperature $\left(60^{\circ} \mathrm{C}\right.$ up to $\left.180^{\circ} \mathrm{C}\right)$ and spin coating techniques wwere used to form the PMMA:TiO2 nanocomposite film. The insulation properties of the nanocomposite film were characterized using high voltage test (DC and AC breakdown strength) to identify which nanocompoiste film has the good insulation properties. In addition, different types of electrodes are also used to to measure the insulation properties of nanocompoiste film. The structural properties of PMMA:TiO2 nanocomposite films were characterized using atomic force microscopy (AFM). Results from HV test shows that the annealing temperature affected the insulation properties PMMA:TiO2 nanocomposite film. By increasing the annealing temperature, the insulation properties decreased. Film anneal at $120 \mathrm{oC}$ has the good insulation compare to other temperature. 120 oC are the optimize temperature to prepared the PMMA:TiO2 nanocomposite films. Result from different types of electrodes show that sharp tip has high DC breakdown strength compare to spherical electrodes.
\end{abstract}

Copyright $\odot 2018$ Institute of Advanced Engineering and Science. All rights reserved.

\section{Corresponding Author:}

Lyly Nyl Ismail,

Faculty of Electrical Engineering,

UiTM Cawangan Pulau Pinang, Jalan Permatang Pauh,

13500 Seberang Perai, Pulau Pinang.

\section{INTRODUCTION}

According to International Electrotechnical Commission, IEC 60038(2002), high voltage (HV) is defined as a system with greater than $1000 \mathrm{~V}$ alternating current (AC) and greater than $1200 \mathrm{~V}$ direct current (DC) [1]. In order to maintain the flow of electric current, insulator is required to insulate the conductors. Insulators are also important to prevent the flow of current to the undesired path in the system. In HV system, the insulation quality plays an important role because it can be a major contribution to power system breakdown.

Organic material (OM) or polymer is widely used as solid insulation in HV. Polymer is a material that has a molecular structure that bonded together and produces a long chain of structure. Each polymer has different characteristics in terms of their physical and chemical structure and also in terms of electrical and mechanical behavior [2]. Thermoplastics, poly amide, polyacrylamide, polycarbonate, and polyethylene are examples of polymer material that is being used as insulation in HV applications [3]. Despite its advantages, 
polymer has disadvantages which is low dielectric properties. Recent studies show solution to overcome the problem in pure polymer is by adding filler into pure polymer material to form a nanocomposite material which is nanodielectric. Properties of nanodielectric material has exhibit more attractive electrical characteristic as compared to polymer itself. Nanodielectric is predicted to improve the electrical performance of the currently available high voltage electrical insulation systems for example resistive to partial discharge, has high permittivity and low loss tangent [20], [25]-[27]. In this research, nanocomposite between poly methyl metacrylate (PMMA) as a matrix and titanium dioxide (TiO2) as a filler were used to form nanodielectric film [4], [22], [24]. TiO2 as filler were chosen due to it is proven to increased dielectric properties of PMMA material [1], [9].

In this research, the PMMA:TiO2 nanodielectric film were further investigate to be used as insulation in the HV applications. The nanodielectric film were fabricate by using spin coating technique.The effect of annealing temperature during the fabrication of nanodielectric film were investigate to identify optimized temperature to fabricate the nanodielectric film. The insulation characteristics of nanodielectric film were investigated using HV test which involved in DC and AC breakdown test.

\section{RESEARCH METHOD}

This section explains in detail the overall procedure of the proposed research work. The first part will elaborately describe the preparation of PMMA:TiO2 nanocomposite film. Followed by that, the following section will explain on the characteristic of the film.

\subsection{Preparation of PMMA: $\mathrm{TiO}_{2}$ nancomposite film}

PMMA powders with molecular weight, (Mw) of 120,000 were purchased from Sigma Aldrich, $\mathrm{TiO} 2$ nanopowder by Aldrich Chemicals and toluene from Sigma Aldrich. The PMMA:TiO2 nanocomposite solution was prepared by mixing $0.15 \mathrm{~g}$ PMMA powder with $2 \mathrm{wt} \% \mathrm{TiO} 2$ nanopowder into the glass bottle. The mixer were dissolve into $5 \mathrm{ml}$ toluene solvent. Three drops of trimethoxymethylsilane (TMOMS) were used as the stabilizer between PMMA and $\mathrm{TiO} 2$ nanopowder and toluene solvent. The solution were sonicated in ultrasonic at $50{ }^{\circ} \mathrm{C}$ for 30 minutes. Then, the solution was left at room temperature for 24 hours before being spin coated (speed of $1500 \mathrm{rpm}$ for $60 \mathrm{sec}$ ) on a glass to form PMMA:TiO2 nanocomposite film. Then, the sample was annealed at different temperature $\left(60{ }^{\circ} \mathrm{C}, 90^{\circ} \mathrm{C}, 120^{\circ} \mathrm{C}, 150{ }^{\circ} \mathrm{C}\right.$ and $\left.180{ }^{\circ} \mathrm{C}\right)$ for 1 hour to restructure the PMMA:TiO2 nanocomposite films [9].

\subsection{PMMA:TiO2 nancomposite film characteristics}

The film characteristics are divided into 2 parts: (1) the structural characteristic and (2) Insulation characteristics. Structural characteristics is basically to obtain the film thickness and morphology of PMMA:TiO2 film. The film thickness is characterized using surface profiler. The film morphology is determined by atomic force microscopy (AFM).

Insulation characteristics is basically to obtain the solid insulation properties of PMMA:TiO2 film. The insulation properties is obtained by applying DC and AC breakdown tests to the film. During this test, two types of electrodes are used as shown in Figure 1 and Figure 2 which are spherical shaped electrode and sharped tip shaped electrode. Voltage is injected for 5 times on each sample (film). A pair of needle-to-plane electrodes is employed. The nanocomposite film is being tested by using different size of electrodes. An alternating current is applied on the different electrode while the plane electrode is grounded. The partial discharge measurement is taken while AC breakdown voltage test is conducted.

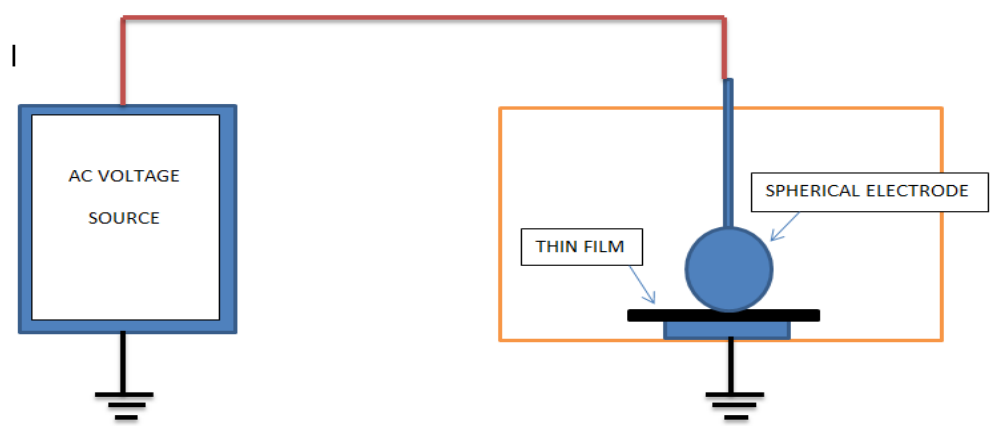

Figure 1. High voltage test set up for spherical electrode shape 


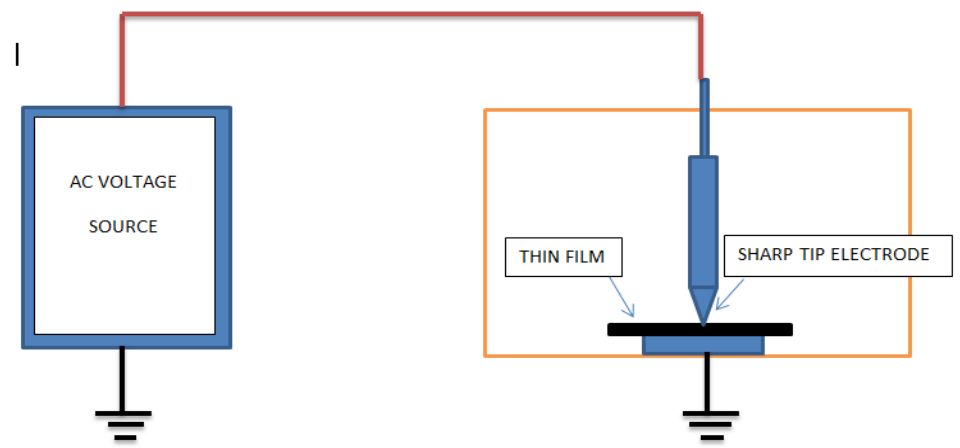

Figure 2. High voltage test set up for sharp tip electrode shape

\section{RESULTS AND ANALYSIS} conducted.

This section will discuss in detail the findings contained from the experiment that has been

\subsection{Structural Properties of PMMA:TiO2 nanodielectric film}

Figure 3 shows the film thickness versus surface roughness of PMMA:TiO2 nanodielectric film for different annealing temperature. As the annealing temperature is increased, the thickness of the sample decreases. The reduction in the nanodielectric film thickness is due to the solution evaporation [9]. Therefore, as the annealing temperature increases, the thickness of the $\mathrm{PMMA}^{\mathrm{TiO}}{ }_{2}$ film is decreases.

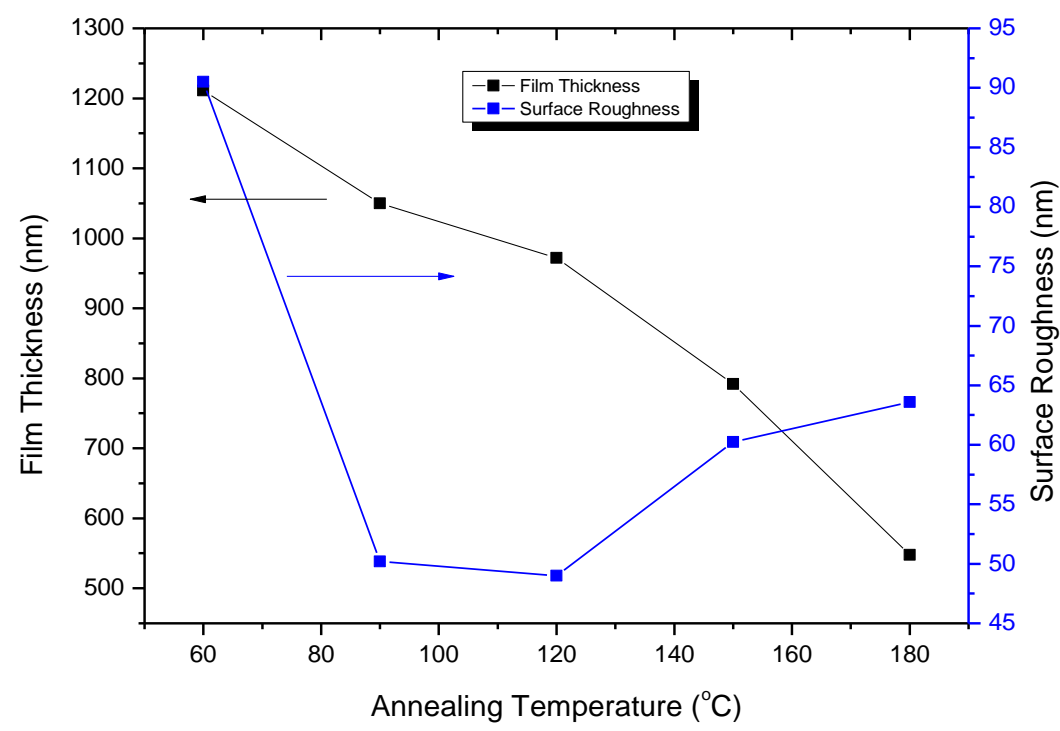

Figure 3. Film thickness and surface roughness of $\mathrm{PMMA}_{\mathrm{TiO}}$ nanocomposite film at difference annealing temperature

Figure 4 shows the AFM images of PMMA:TiO2 nanodielectric film at different annealing temperature. As annealing temperature increases, the surface roughness decreases from $60{ }^{\circ} \mathrm{C}$ to $120{ }^{\circ} \mathrm{C}$ and it increases again from $150{ }^{\circ} \mathrm{C}$ to $180{ }^{\circ} \mathrm{C}$. It can be seen that, as the anneal temperature increases from $60{ }^{\circ} \mathrm{C}$ to $120^{\circ} \mathrm{C}$, the surface roughness decreased. When annealed temperature continue to increase until $140^{\circ} \mathrm{C}$ and above, the surface of PMMA:TiO2 film become rougher. This condition is due to the agglomeration of TiO2 nanofiller. As the temperature increases, the film become dense which lead to existence of the agglomeration of particles. Agglomeration are the white particles formed during the fabrication process [5]. 


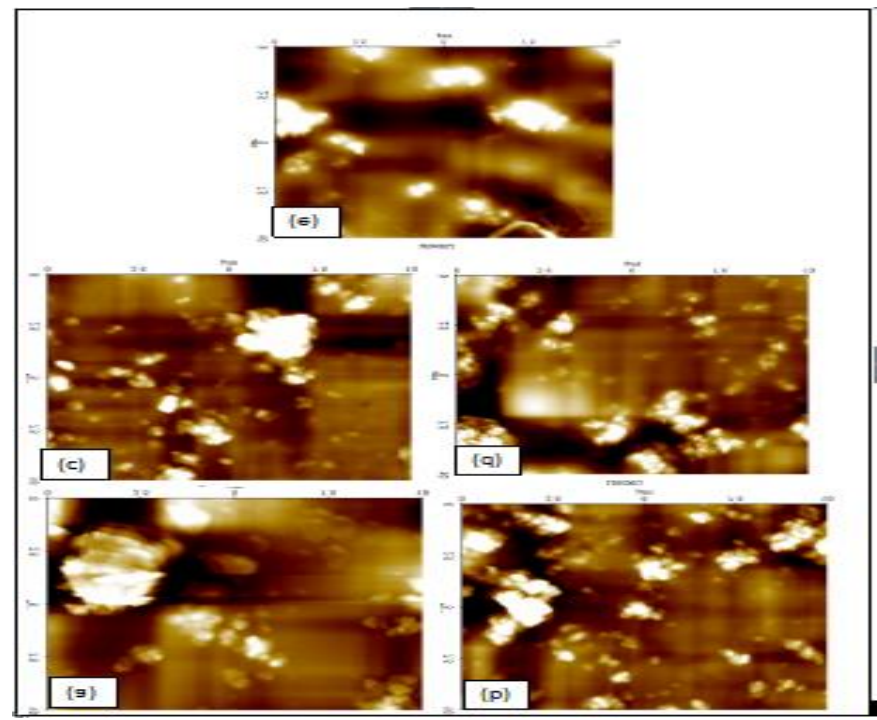

Figure 4. PMMA: $\mathrm{TiO}_{2}$ nanocomposite films with different annealing temperature using $\mathrm{AFM}$ (a) $60^{\circ} \mathrm{C}$ (b) $90^{\circ} \mathrm{C}$ (c) $120^{\circ} \mathrm{C}$ (d) $150^{\circ} \mathrm{C}$ (e) $180^{\circ} \mathrm{C}$

\subsection{Insulation Properties of PMMA:TiO2 nancomposite film}

Figure 5 shows the graph of breakdown voltage for $\mathrm{PMMA}_{\mathrm{TiO}}$ nanocomposite film with different annealing temperature. During the testing, sharp tip electrode is used. As the annealing temperature increases from $60^{\circ} \mathrm{C}$ to $120^{\circ} \mathrm{C}$, the breakdown voltage also increases significantly. Nevertheless, when temperature continue to increase from $140{ }^{\circ} \mathrm{C}$ and above, the decrements in the breakdown voltage were observed. The decrement in the breakdown voltage is due to the PMMA:TiO2 film start to perforated. The PMMA:TiO2 film perforated is due to PMMA matrix can only withstand a maximum temperature of $150{ }^{\circ} \mathrm{C}$ [9]. When the film start to perforated, the breakdown voltage started to decrease and lead to film defect and provide path for voltage to break in through the insulator [10].

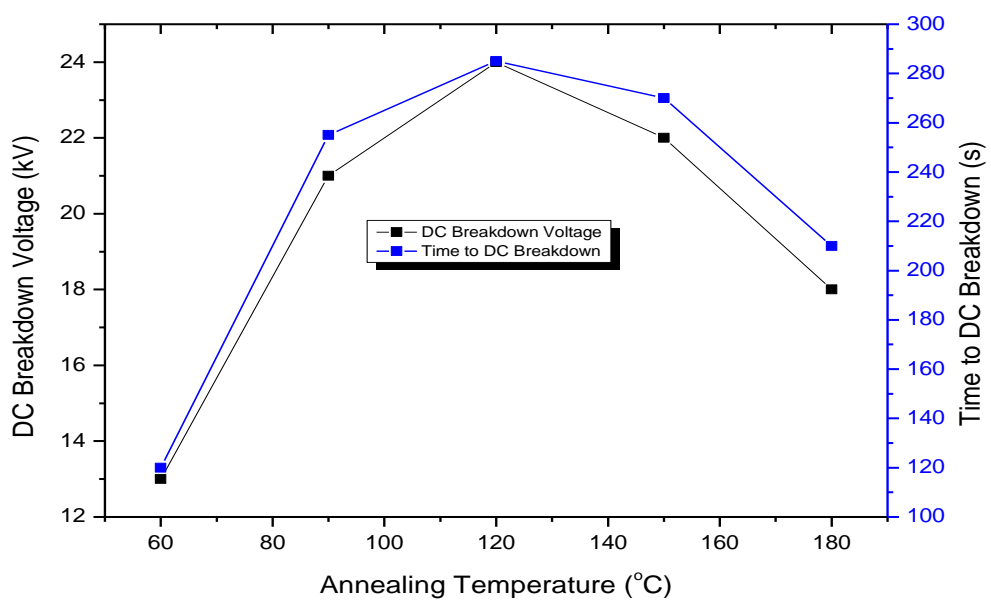

Figure 5. DC Breakdown voltage and time to DC breakwon of PMMA:TiO2 film with difference annealing temperature

Figure 5 also shows time taken for $\mathrm{DC}$ breakdown to occur for $\mathrm{PMMA}_{\mathrm{TiO}}$ nanocomposite film with different annealing temperature. PMMA:TiO2 with annealing temperature of $60^{\circ} \mathrm{C}$ is breakdown in a short period. It took for about 120 seconds to reach the breakdown. PMMA:TiO2 annealed at $120^{\circ} \mathrm{C}$ has the longest period taken to reach breakdown which is within 280 seconds. However, $120^{\circ} \mathrm{C}$ is not the maximum annealing temperature in this research. There are also $140^{\circ} \mathrm{C}$ and $180^{\circ} \mathrm{C}$ annealing temperature but this two 
annealing temperature has a short breakdown time as compared to the sample annealed at $120^{\circ} \mathrm{C}$. On top of that, breakdown time of each samples is affected by their annealing temperature. This is due to the effect of annealing temperature on the nanostructure of each samples. According to other researcher, there are large agglomeration contains lots of large voids defect and impurities on the surface of nanocomposite material[11]. Although for many years nanocomposite research has been carried out, the subject on agglomeration of nanoparticles remains an intensive debate [6]. In conjunction with agglomeration, it can be related with the surface roughness [12]. The rougher the surface of that sample, the shortest the time taken to reach breakdown and vice versa. It can be concluded that the time taken for each sample to reach breakdown is affected by the agglomeration on that sample due to annealing process.

Figure 6 shows a graph of $\mathrm{PMMA}_{\mathrm{TiO}}$ film AC breakdown strength on each annealing temperature. It tells us as annealing temperature increases, the breakdown strength also increases. The increases of breakdown strength is due to the reduction of $\mathrm{PMMA}^{\mathrm{T}} \mathrm{TiO}_{2}$ film thickness. Reduction in the breakdown strength indicate the PMMA:TiO2 film has high relative permittivity [8].

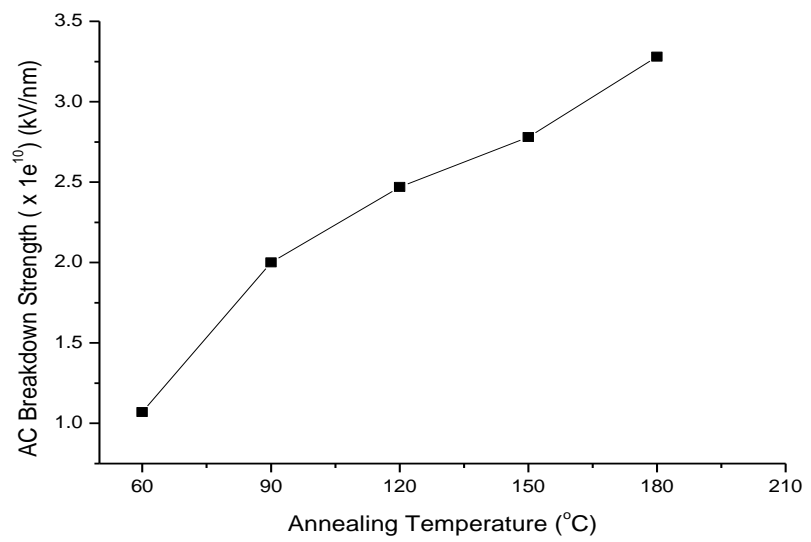

Figure 6. AC Breakdown strength of PMMA:TiO2 film anneal at different temperature

Figure 7 shows DC breakdown voltage (BDV) for $\mathrm{PMMA}_{\mathrm{TiO}}$ with different annealing temperature tested by using two different types of electrode. Spherical shape and sharp tip electrode is used to investigate the rating of breakdown voltage on a same material with different type of electrode. It also can be observed that BDV with sharp tip electrode exhibit higher values as compared to spherical shaped electrode. PMMA: $\mathrm{TiO}_{2}$ annealed at $60^{\circ} \mathrm{C}$ has the lowest $\mathrm{BDV}$ and $\mathrm{PMMA}: \mathrm{TiO}_{2}$ annealed at $180^{\circ} \mathrm{C}$ has the greatest BDV based on both type of electrode. In conclusion, sharp tip electrode gives greater BDV than spherical electrode for about twice the lowest BDV value. This is because breakdown of polymeric materials decreases as the electrode area increase because of the electric field enhancement [3]. The treeing process in the voids may excitedly initiate as the area under the electrode is increases.

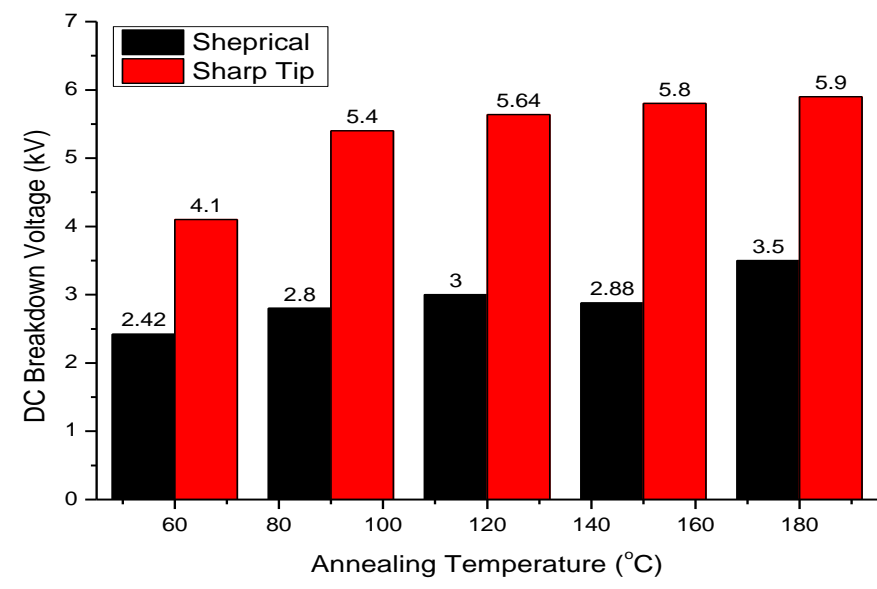

Figure 8. DC breakdown voltage of PMMA:TiO2 film with electrode shapes 
Partial discharge (PD) are generally a result of local electrical stress concentration in the insulation or on the surface of insulation and often accompanied by the emission of sound,light, heat or chemical reactions. PD are small sparks that occur within the insulation medium. These discharge degrade the insulation properties and as a results to insulation failure. PD can be initiated by voids or other impurities excist in the insulation system. PD causes the insulator to deteriorate progressively and can lead to electrical breakdown [13-15]. Figure 9 shows that the PD of PMMA:TiO2 film at different anneal temperature. As annealing temperature increases from $60^{\circ} \mathrm{C}$ to $120^{\circ} \mathrm{C}$, the PD increase gradually. It happen due to the strength of the nanocomposite film which is affected by the crystallinity of $\mathrm{PMMA}$ and $\mathrm{TiO}_{2}$ particles arrangement [6]. Crystallinity and crystallites of a film will increased with annealing temperature [16]. Nevertheless, the partial discharge decreases after the annealing temperature is increased more than $120^{\circ} \mathrm{C}$ because of the behavior of PMMA itself in which it started to melt between temperature of $150^{\circ} \mathrm{C}$ to $160^{\circ} \mathrm{C}[9]$.

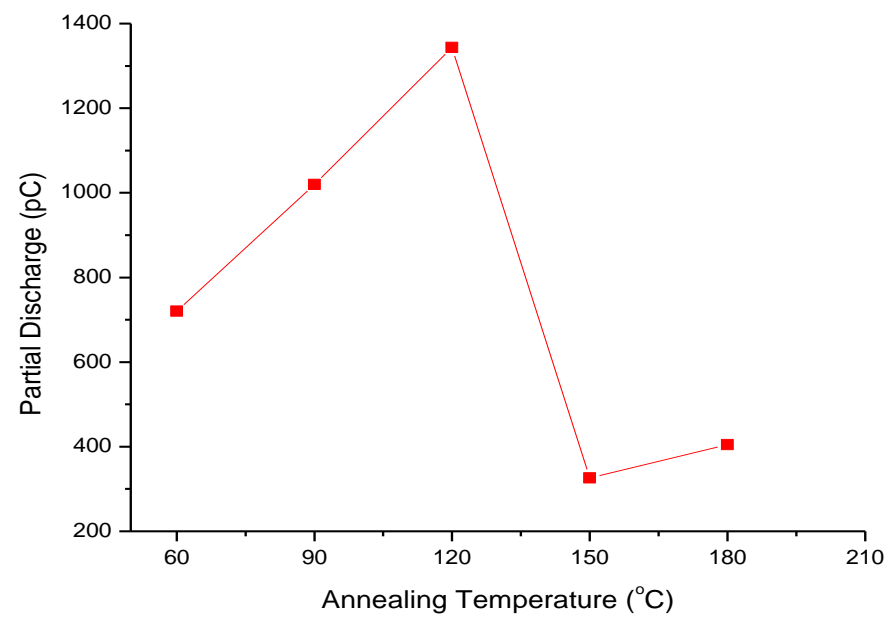

Figure 8. Partial Discharge data for PMMA:TiO2 nanocomposite film

\section{CONCLUSION}

As conclusion, the insulation properties of PMMA:TiO2 nanodielectric film were successfully characterized. Annealing temperature thus affected the performance of PMMA:TiO2 nanodielectric film as insulation in HV. Result show that PMMA:TiO2 nanodielectric film anneal at $120 \mathrm{oC}$ has good insulation properties compare to other temperature. When the nanodielectric film anneal at temperature above $150 \mathrm{oC}$, the insulation properties degraded significantly. Different electrode used also affected the insulation propertier of nanocomposite film. Sharp tip has the highest breakdown voltage compare to sheprical electrode.

\section{ACKNOWLEDGMENT}

The authors would like to acknowledge Universiti Teknologi MARA Cawangan Pulau Pinang and NANO-SciTech Centre, UiTM Shah Alam for providing us the grant the use their AFM equipment.

\section{REFERENCES}

[1]. IEC, "Efficient electrical energy transmission and distribution", p. 24, 2007.

[2]. Pleşa, P. Noţingher, S. Schlögl, C. Sumereder, and M. Muhr",Properties of Polymer Composites Used in HighVoltage Applications", Polymers (Basel)., vol. 8, no. 5, p. 173, 2016.

[3]. M. A. Douar, A. Beroual, and X. Souche, "Comparative study of AC breakdown voltage for various polymers: Influence of electrodes shape, thermal and hydrothermal ageing," ICHVE 2014 - 2014 Int. Conf. High Volt. Eng. Appl., no. ii, pp. 0-3, 2014.

[4]. L. N. Ismail, S. A. Farahiyah, Z. Habibah, S. H. Herman, and M. Rusop, "Dielectric and physical properties of PMMA : TiO 2 thin films by varying TiO 2 concentration," pp. 259-262, 2012.

[5]. T. Tanaka, G. C. Montanari, and R. Mulhaupt, "Polymer nanocomposites as dielectrics and electrical insulationperspectives for processing technologies, material characterization and future applications," IEEE Trans. Dielectr. Electr. Insul., vol. 11, no. 5, pp. 763-784, 2004. 
[6]. K. Y. Lau, A. S. Vaughan, and G. Chen, "Nanodielectrics: Opportunities and challenges," IEEE Electr. Insul. Mag., vol. 31, no. 4, pp. 45-54, 2015.

[7]. W. Yan, Z. J. Han, B. T. Phung, F. Faupel, and K. K. Ostrikov, "High-voltage insulation organic-inorganic nanocomposites by plasma polymerization," Materials (Basel)., vol. 7, no. 1, pp. 563-575, 2014.

[8]. K. Y. Lau, N. A. Muhamad, N. Bashir, Y. Z. Arief, and M. A. M. Piah, "Modeling of Polymer Nanocomposites: Permittivity vs . Electric Field Intensity," pp. 140-145, 2014.

[9]. L. N. Ismail, Z. Habibah, S. H. Herman, and M. Rusop, "Effect of annealing temperature on electrical properties of poly (methyl methacrylate): titanium dioxide nanocomposite films using spin coating deposition technique," IOP Conf. Ser. Mater. Sci. Eng., vol. 64, p. 12051, 2014.

[10]. Y. Uozumi, Y. Kikuchi, N. Fukumoto, M. Nagata, Y. Wakimoto, and T. Yoshimitsu, "Characteristics of partial discharge and time to breakdown of nanocomposite enameled wire," Annu. Rep. - Conf. Electr. Insul. Dielectr. Phenomena, CEIDP, pp. 228-231, 2007.

[11]. F. Tian, Q. Lei, X. Wang, and Y. Wang, "Investigation of electrical properties of LDPE/ZnO nanocomposite dielectrics," IEEE Trans. Dielectr. Electr. Insul., vol. 19, no. 3, pp. 763-769, 2012.

[12]. N. a El-zaher, M. S. Melegy, and O. W. Guirguis, "Thermal and Structural Analyses of PMMA / $\mathrm{TiO}_{2}$ Nanoparticles Composites," Nat. Sci., vol. 6, no. July, pp. 859-870, 2014.

[13]. C. Mayoux and M. Goldman, "Partial discharges in solid dielectrics and corona discharge phenomena," J. Appl. Phys., vol. 44, no. 9, pp. 3940-3944, 1973.

[14]. D. E. Selvaraj, "Partial discharge characteristics of enamel filled with micro and nano composite of $\mathrm{SiO} 2$ and TiO2,” Int. J. Sci. Eng. Appl., vol. 1, no. 2, pp. 95-101, 2013. 